Check for updates

Cite this: RSC Adv., 2017, 7, 26496

\section{Ambient temperature induced Diels-Alder crosslinked networks based on controlled methacrylate copolymers for enhanced thermoreversibility and self-healability $\dagger$}

\author{
Sungmin Jung, ${ }^{a}$ So Young Kim, ${ }^{b}$ Jin Chul Kim, ${ }^{b}$ Seung Man Noh ${ }^{b}$ \\ and Jung Kwon Oh (D) *a
}

\begin{abstract}
The development of covalently-crosslinked dynamic (reversible) networks has been extensively explored due to their built-in ability to self-repair damages, which prevents catastrophic failure of highperformance materials. Here, we report effective thermoreversible crosslinked networks fabricated at room or mild temperature from reactive blends consisting of a controlled methacrylate copolymer having maleimide pendants (CoPMA) and a trifunctional furan (TFu). Well-defined CoPMA is synthesized by controlled radical polymerization, ensuring predetermined chain lengths with narrow molecular weight distribution, and following post-modification through deprotection of pendant furan-protected maleimide groups, ensuring conversion to the corresponding maleimide pendants. The well-defined CoPMA is reactive to different amounts of TFu as a model polyfuran to form dynamic networks at ambient temperature through a click type Diels-Alder (DA) reaction. Comprehensive analyses indicate that the mole ratio of furan/maleimide group is an important parameter that significantly influences network flexibility. The developed dynamic networks crosslinked with thermo-labile DA cycloadduct linkages enable the dissociation and recombination through retro DA (rDA)/DA reactions at elevated temperatures. Such thermoreversibility, combined with balanced flexibility, allows for the development of dynamic network exhibiting effective self-healability at as low as $110{ }^{\circ} \mathrm{C}$ with great mechanical property restoration as well as healing elasticity through reversible restoration of viscoelastic properties.
\end{abstract}

Received 13th April 2017 Accepted 2nd May 2017 DOI: $10.1039 / \mathrm{c} 7 \mathrm{ra04222a}$

rsc.li/rsc-advances repaired. A promising solution that have been extensively explored is to develop dynamic (or reversible) crosslinked networks that retains self-healing upon external damages, thus improving their lifetime, energy efficiency, and environmental impact. ${ }^{4-6}$ Taking the benefits from an initial approach based on microcapsule or vascular network technologies, ${ }^{7-9}$ the promising approach involves the incorporation of reversible covalent or supramolecular crosslinkages into the design of dynamic thermosets. In addition to non-covalent interactions (or reversible physical crosslinking), ${ }^{10-30}$ the dynamic covalent bonds (or reversible chemical crosslinking) ${ }^{31-42}$ and recently their combination ${ }^{43-45}$ have shown the repeatable and multiple occurrence of self-healing in intrinsic self-healing systems.

Typical dynamic chemical crosslinkages based on disulfide, hindered urea, and alkoxyamine chemistries are composed of flexible bonds. In contrast, the cycloadducts formed by DA reaction are based on newly-formed carbon-carbon bonds between an electron-rich diene and an electron-poor dienophile. Consequently, the thermally-induced DA-crosslinked networks provide enhanced mechanical properties, compared with other networks. ${ }^{46,47}$ Further, the formed DA linkages in the networks can be dissociated to the corresponding diene and
${ }^{a}$ Department of Chemistry and Biochemistry, Concordia University, Montreal, Quebec, Canada H4B 1R6.E-mail: john.oh@concordia.ca

${ }^{b}$ Research Center for Green Fine Chemicals, Korea Research Institute of Chemical Technology, Ulsan 44412, Republic of Korea

$\dagger$ Electronic supplementary information (ESI) available. See DOI: $10.1039 / \mathrm{c} 7 \mathrm{ra} 04222 \mathrm{a}$

\footnotetext{
networks can be dissociated to the corresponding diene and
} 
dienophile through rDA reaction within the networks at elevated temperatures. Utilizing rDA and following DA reactions, the DA-crosslinked networks can be displaced by their dissociation and reformed by reconnection through void fillingthermoreversible process upon controlled heating. Because of the maleimide/furan pair being highly reactive to cycloaddition as well as being shifted of its DA/rDA equilibrium at low temperatures, thermally-reversible $\mathrm{DA} / \mathrm{rDA}$ chemistry utilizing maleimide as a dienophile and furan as a diene has been extensively explored to develop thermally-induced self-healable networks. Most of DA-crosslinked networks were fabricated through step-growth polyaddition or coupling reaction of polymaleimides and polyfurans. ${ }^{48-57}$

Of our interests are thermo-labile networks based on reactive methacrylate copolymers. The nature of the polymethacrylate backbones of carbon-carbon single bonds, the high molecular weight of polymeric chains, and the facile copolymerization with soft monomers allow for tuning the balance of rigidity and flexibility of methacrylate networks. Early reports describe the synthesis of methacrylate copolymers having furan pendants by chain-growth polymerization $^{58-60}$ or post-modification; ${ }^{61}$ these copolymers then reacted with a bismaleimide crosslinker to form DA-crosslinked networks. Recently, the synthesis of methacrylate copolymers having both furan and furan-protected maleimide pendants ${ }^{62-64}$ as well as a methacrylate homopolymer having pendant furanprotected maleimide groups ${ }^{65}$ has been reported. To exhibit enhanced mechanical properties and thermoreversible selfhealability, however, these systems required elevated temperatures $\left(>120{ }^{\circ} \mathrm{C}\right)$ for the formation of DA-crosslinked networks. This is mainly because of the deprotection of furan-protected maleimide groups to generate the corresponding maleimide groups in the copolymers, which in situ react with polyfurans. We have envisioned that the synthesis of methacrylate copolymers with bare maleimide pendants could allow for the fabrication of DA-crosslinked networks with polyfurans at ambient or even room temperatures. This approach could be beneficial in constructing high-performance materials for industrial applications; more specifically our polymers could be considered as self-healable adhesives in surface coating formulations that can protect automobiles and heavy-duty metals.

In this work, we have explored an approach utilizing controlled radical polymerization and post-modification to synthesize a series of methacrylate copolymers having different densities of reactive maleimide and inert ethylhexyl pendants (CoPMAs). As a model polyfuran, a new tri-functional furan (TFu) was also synthesized by a click-type thermally-induced thiol-ene reaction. The occurrence of DA-crosslinking reactions of the maleimide and the furan groups in reactive blends composed of controlled CoPMA with TFu at ambient temperatures was characterized with not only gel content measurement and sol-gel transition but also spectroscopic and thermal analysis. The resultant DA-crosslinked networks formed at different mole ratios of furan/maleimide groups were further analyzed for thermoreversibility and self-healability as well as self-healing viscoelastic and mechanical properties through DA/ rDA reactions (Scheme 1).
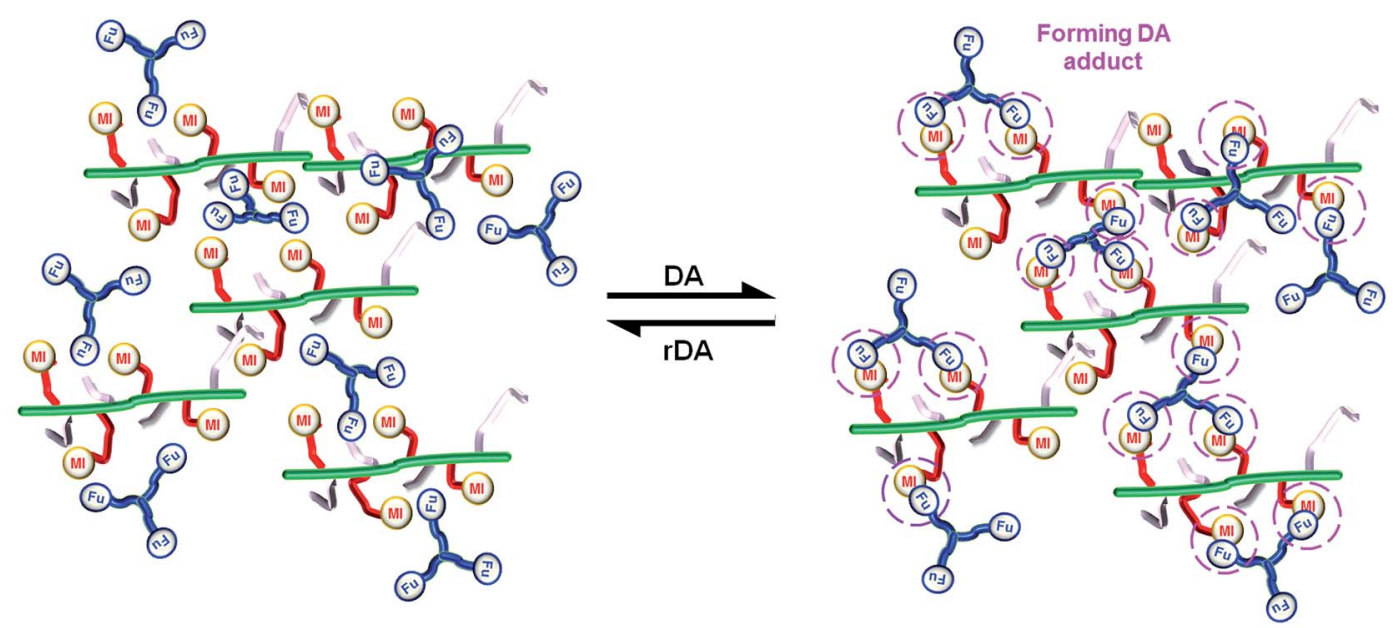

Reactive blend of CoPMA and TFu

DA-crosslinked network

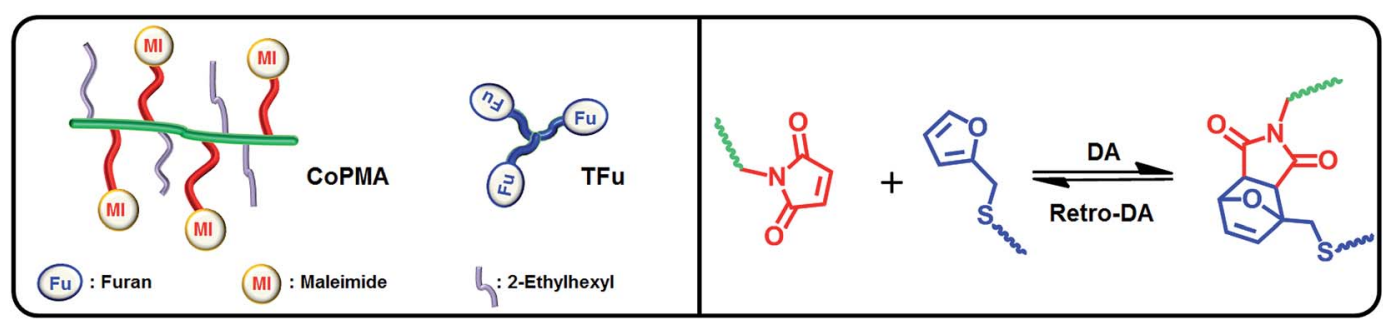

Scheme 1 Thermoreversible DA/rDA reactions for self-healing of dynamic networks prepared from a reactive mixture containing CoPMA having reactive maleimide pendants and TFu. 


\section{Experimental}

\section{Instrumentation and analyses}

${ }^{1} \mathrm{H}-\mathrm{NMR}$ spectra were recorded using a $500 \mathrm{MHz}$ Varian spectrometer. The $\mathrm{CDCl}_{3}$ singlet at $7.26 \mathrm{ppm}$ and DMSO- $d_{6}$ quintet at $2.5 \mathrm{ppm}$ were selected as the reference standards. Molecular weight and molecular weight distribution were determined by gel permeation chromatography (GPC) with a Viscotek VE1122 pump and a refractive index (RI) detector. Two PolyAnalytik columns (PAS-103L and 105L, designed to determine molecular weight up to $2000000 \mathrm{~g} \mathrm{~mol}^{-1}$ ) were used with THF as eluent at $30{ }^{\circ} \mathrm{C}$ at a flow rate of $1 \mathrm{~mL} \mathrm{~min}^{-1}$. Linear poly(methyl methacrylate) standards were used for calibration. Aliquots of polymer samples were dissolved in THF. The clear solutions were filtered using a $0.25 \mu \mathrm{m}$ PTFE filter to remove any solvent-insoluble species. A drop of anisole was added as a flow rate marker.

\section{Differential scanning calorimetry (DSC)}

Thermal properties including glass transition temperature $\left(T_{\mathrm{g}}\right)$ of polymers and crosslinked films were measured with a TA Instruments DSC Q20 differential scanning calorimeter. Samples were dried under vacuum for $24 \mathrm{~h}$ at room temperature to remove residual solvents. Temperature range was from -70 to $200{ }^{\circ} \mathrm{C}$ with heating and cooling cycles conducted at a rate of $10{ }^{\circ} \mathrm{C} \min ^{-1}$ (cycles: cool to $-70{ }^{\circ} \mathrm{C}$, heat up to $200{ }^{\circ} \mathrm{C}\left(1^{\text {st }}\right.$ run), cool to $-70{ }^{\circ} \mathrm{C}$, heat up to $200{ }^{\circ} \mathrm{C}\left(2^{\text {nd }}\right.$ run $)$, and cool to $\left.25{ }^{\circ} \mathrm{C}\right)$. The $T_{\mathrm{g}}$ values were determined from the $2^{\text {nd }}$ heating run.

\section{Thermogravimetric analysis (TGA)}

TGA measurements were carried out using a TA instruments Q50 analyzer. Typically, dried samples (5-10 mg) were placed into a platinum pan and heated from 25 to $800{ }^{\circ} \mathrm{C}$ at a heating rate of $20{ }^{\circ} \mathrm{C} \mathrm{min}^{-1}$ under nitrogen flow.

\section{Materials}

3-Phenyl-1-propanol (PP-OH, 98\%), $\alpha$-bromoisobutyryl bromide (Br-iBuBr, 98\%), tin(II) 2-ethylhexanoate ( $\mathrm{Sn}(\mathrm{II}) \mathrm{EH}_{2},>92.5 \%$ ), triethylamine $\left(\mathrm{Et}_{3} \mathrm{~N}, 99.5 \%\right)$, furfuryl mercaptan (Fu-SH, 99\%), $N$-(3-dimethylaminopropyl)- $N$ '-ethylcarbodiimide hydrochloride (EDC, $\geq 98.0 \%$ ), 4-(dimethylamino)pyridine (DMAP, $\geq 99 \%$ ), 2,2'-azobis(2-methylbutyronitrile) (AMBN, >98\%), trimethylolpropane trimethacrylate (TMA, technical grade), and furan $(\geq 99 \%)$ from Sigma Aldrich as well as maleic anhydride $(>98 \%)$ from Fluka were used as received. 2-Ethylhexyl methacrylate (EHMA, 98\%) purchased from Aldrich was passed through basic alumina column to remove inhibitors before polymerization. Tris(2-pyridylmethyl)amine (TPMA) was synthesized as described elsewhere. ${ }^{66}$ A methacrylate having pendant furan-protected maleimide (MIMA) ${ }^{64}$ was synthesized with a slight modification as described in ESI. $\dagger$

\section{Synthesis of 3-phenylpropyl 2-bromo-2-methylpropanoate (PP-Br)}

$\mathrm{Br}$-iBuBr (9.3 g, $40.4 \mathrm{mmol})$ was added to a clear solution consisting of PP-OH (5.0 g, $35.7 \mathrm{mmol})$, DMAP (0.45 g, $3.67 \mathrm{mmol})$, and $\mathrm{Et}_{3} \mathrm{~N}(5.6 \mathrm{~g}, 55.0 \mathrm{mmol})$ in methylene chloride $(128 \mathrm{~mL})$ at room temperature. The resulting mixture was stirred at room temperature for $14 \mathrm{~h}$, and then diluted with diethyl ether. The yellow precipitates as byproducts were removed by vacuum filtration and organic solvents were removed using a rotary evaporation. The residues were purified by silica column chromatography with a mixture of ethyl acetate/hexane $(1 / 5 \mathrm{v} / \mathrm{v})$. The product was collected as the first of a total three bands from a silica gel column: yield $=9.3 \mathrm{~g}(89 \%)$ and $R_{\mathrm{f}}=0.3$ on silica $(1 / 5$ ethyl acetate/hexane).

\section{Synthesis of CoPMIMA by ATRP}

For the synthesis of CoPMIMA-2 as a typical example, $\mathrm{PP}-\mathrm{Br}$ (0.12 g, $0.43 \mathrm{mmol})$, MIMA (1.5 g, $5.41 \mathrm{mmol})$, EHMA (1.07 g, $5.41 \mathrm{mmol}),[\mathrm{Cu}(\mathrm{II}) \mathrm{TPMABr}] \mathrm{Br}(11.1 \mathrm{mg}, 22 \mu \mathrm{mol})$, TPMA $(12.6 \mathrm{mg}, 43 \mu \mathrm{mol})$, and anisole $(7.76 \mathrm{~mL})$ were mixed in a $25 \mathrm{~mL}$ Schlenk flask. The resulting mixture was deoxygenated by purging under nitrogen for $40 \mathrm{~min}$. A nitrogen-prepurged $\mathrm{Sn}$ (II) $\mathrm{EH}_{2}$ solution in anisole $\left(0.5 \mathrm{~mL}, 0.234 \mathrm{~g} \mathrm{~mL}^{-1}\right)$ was injected into reaction mixture and placed in an oil bath preheated at given temperature $\left(35{ }^{\circ} \mathrm{C}\right)$ to initiate polymerization. Aliquots were taken from polymerization mixture at regular intervals to determine conversion using ${ }^{1} \mathrm{H}-\mathrm{NMR}$. Polymerization was stopped by cooling the reaction mixture in an ice bath and exposing to air.

For purification, the as-synthesized polymer solution was precipitated from $\mathrm{MeOH}$ three times to remove unreacted monomers. The precipitate was dissolved in minimal amount of chloroform and then passed through a column filled with basic alumina to remove residual copper species. Solvents were removed by rotary evaporation and the residues were dried in a vacuum oven at room temperature for $24 \mathrm{~h}$.

Similar procedure was applied with the use of $\mathrm{PP}-\mathrm{Br}$ (123.4 mg, 433 mol), MIMA (1.5 g, $2.7 \mathrm{mmol}$ ), EHMA (1.61 g, $8.1 \mathrm{mmol}),[\mathrm{Cu}(\mathrm{II}) \mathrm{TPMABr}] \mathrm{Br}(11.1 \mathrm{mg}, 22 \mu \mathrm{mol})$, TPMA (12.6 mg, $43.3 \mu \mathrm{mol})$, and anisole $(9.3 \mathrm{~mL})$ for the synthesis of CoPMIMA-1, and PP-Br (123.4 mg, $433 \mu \mathrm{mol})$, MIMA (1.5 g, 8.1 mmol), EHMA (0.54 g, $2.7 \mathrm{mmol})$, [Cu(II)TPMABr]Br (11.1 mg, 22 $\mu \mathrm{mol})$, TPMA $(12.6 \mathrm{mg}, 43.3 \mu \mathrm{mol})$, and anisole $(6.1 \mathrm{~mL})$ for synthesis of CoPMIMA-3.

\section{Synthesis of CoPMA}

The purified, dried CoPMIMA (2 g) dissolved in DMSO (5 mL) was heated at $120{ }^{\circ} \mathrm{C}$ under stirring. After $3 \mathrm{~h}$, the polymer solution was cooled down to room temperature and then precipitated from a mixture of $\mathrm{MeOH} /$ water $(1.5 / 1 \mathrm{v} / \mathrm{v})$. The precipitates were dried in vacuum oven at room temperature for $16 \mathrm{~h}$.

\section{Synthesis of TFu}

TMA (3.0 g, $16 \mathrm{mmol})$, AMBN (0.52 g, $3.2 \mathrm{mmol})$, Fu-SH (20.9 $\mathrm{mL}, 207 \mathrm{mmol})$, and anhydrous DMF $(31 \mathrm{~mL})$ were placed in a Schlenk flask. The resulting mixture was then stirred at $75{ }^{\circ} \mathrm{C}$ for $24 \mathrm{~h}$, and then cooled down to room temperature. Solvents and excess Fu-SH were removed under reduced pressure. Residues were precipitated from a mixture of deionized water/ 
methanol $(1 / 1.5 \mathrm{v} / \mathrm{v})$ twice. The precipitates were purified by silica column chromatography using a mixture of ethyl acetate/ hexane $(1 / 5 \mathrm{v} / \mathrm{v})$. The product was collected as the third of a total five bands from a silica gel column; yield $=2.6 \mathrm{~g}(40 \%)$ and $R_{\mathrm{f}}=$ 0.3 on silica ( $1 / 5$ ethyl acetate/hexane).

\section{Preparation of crosslinked films through DA reactions}

A series of reactive blends of CoPMA- 2 and TFu at the mole equivalent ratio of pendant furan/maleimide group $=1 / 1,2 / 1$, and $3 / 1$ were prepared by mixing the fixed amount of CoPMA2 (100 mg, corresponding to $0.24 \mathrm{mmol}$ of maleimide group) with different amounts of $\mathrm{TFu}(54,81$, and $162 \mathrm{mg}$, corresponding to $0.08 \mathrm{mmol}, 0.12 \mathrm{mmol}$, and $0.24 \mathrm{mmol}$ of furan group) in anisole $(0.24,0.27$, and $0.4 \mathrm{~mL})$. Their aliquots were dropped on glass slides placed at room temperature for $24 \mathrm{~h}$ and in an oven preset at $60{ }^{\circ} \mathrm{C}$ for $12 \mathrm{~h}$. The resultant crosslinked films were scraped using a knife for further characterization.

\section{Gel content measurements}

Pieces of dried films prepared above (approximately $10 \mathrm{mg}$ ) were mixed with THF $(10 \mathrm{~mL})$ for $48 \mathrm{~h}$. THF was carefully decanted and precipitates were dried in vacuum oven for 2 days. Gel content was calculated as the weight ratio of dried precipitates to initial films.

\section{Sol-gel-sol transitions}

Mixtures of CoPMA-2 (90 mg, $0.21 \mathrm{mmol}$ of maleimide group) with different amounts of TFu in anisole at $43 \mathrm{wt} \%$ were sealed and placed at room temperature for $12 \mathrm{~h}$ to form free-standing gels in vials. For the gel-sol transition experiment, a piece of the dried gel $(110 \mathrm{mg})$ was mixed with DMF $(1 \mathrm{~mL})$ at $11 \mathrm{wt} \%$ and heated up at $150{ }^{\circ} \mathrm{C}$ for $5 \mathrm{~h}$, and then cooled down to room temperature.

\section{Optical microscopy}

Fresh cuts were made using a sharp blade on surfaces of the crosslinked films and annealed in an oven at given temperatures $\left(85,110\right.$, and $\left.150^{\circ} \mathrm{C}\right)$ for $5 \mathrm{~h}$ to $72 \mathrm{~h}$ depending on samples. The occurrence of self-healing in cross-linked networks was followed by an optical microscope (Olympus BX51) coupled with a digital camera.

\section{Rheology measurements}

Viscoelastic properties ( $G^{\prime}$ and $G^{\prime \prime}$ moduli) of DA-crosslinked films were measured on a DHT-2 rheometer (TA Instruments, USA) in amplitude oscillatory shear mode with parallel plate geometry ( $8 \mathrm{~mm}$ diameter). The elasticity of the crosslinked materials were tested by applying cyclic changes of amplitude oscillatory from $5 \%$ strain for $1500 \mathrm{~s}$ to $100 \%$ strain for $500 \mathrm{~s}$. The gap was set to obtain an axial force of $1.5 \mathrm{~N}$ at room temperature and this cycle is repeated three times.

\section{Tensile measurements}

Mechanical properties of polymer samples before and after healing were measured using a tensile testing machine (MCT2150, AND, Japan) at a crosshead speed of $50 \mathrm{~mm} \mathrm{~min}^{-1}$ at room temperature. To prepare dumbbell-shaped specimens (10 $\mathrm{mm} \times 30 \mathrm{~mm} \times 3 \mathrm{~mm}$ ) by a conventional solution casting method, a reactive mixture of CoPMA-2 and TFu (furan/ maleimide mole ratio $=3 / 1$ ) in anisole at $40 \mathrm{wt} \%$ was poured into a mold and placed in a convection oven preset at $60{ }^{\circ} \mathrm{C}$ for $24 \mathrm{~h}$. After being recovered from the mold, the cast specimens were tested for tensile measurements. For quantitative analysis of self-healing, a single cut of $20 \mu \mathrm{m}$ wide and $3 \mathrm{~mm}$ long on the center of the specimens was made using a sharp cutting blade (Dorco, Korea). The resultant specimens were placed at $110{ }^{\circ} \mathrm{C}$ for $2 \mathrm{~h}$ and then $60^{\circ} \mathrm{C}$ for $24 \mathrm{~h}$ (a self-healing condition) and then subjected to tensile tests.

\section{Results and discussion}

\section{Synthesis and thermal properties of CoPMA having maleimide pendants}

Fig. 1a illustrates our approach consisting of two steps to synthesize new multivalent methacrylate copolymers bearing pendant maleimide groups (CoPMA).

The first step is the synthesis of random copolymers having furan-protected maleimide groups. First, $\mathrm{PP}-\mathrm{Br}$ as an initiator was synthesized by a facile coupling reaction of $\mathrm{PP}-\mathrm{OH}$ with $\mathrm{Br}-$ iBuBr in a high yield. Its chemical structure was analyzed with ${ }^{1} \mathrm{H}$ and ${ }^{13} \mathrm{C}-\mathrm{NMR}$ spectra (Fig. S1 $\dagger$ ). Then, Activators ReGenerated by Electron Transfer (ARGET) process for Atom Transfer Radical Polymerization (ATRP) was examined for a monomer mixture of MIMA and EHMA at different mole ratios in the presence of $\mathrm{PP}-\mathrm{Br}$ and $\mathrm{Cu}(\mathrm{II}) / \mathrm{TPMA}$ active complexes. The degree of polymerization (DP) as the initial mole ratio of [MIMA + EHMA $]_{0} /[\mathrm{PP}-\mathrm{Br}]_{0}$ was designed to be $50 / 1$. The polymerization conditions include $[\mathrm{PP}-\mathrm{Br}]_{0} /[\mathrm{CuBr}(\mathrm{II})]_{0} /[\mathrm{TPMA}]_{0} /\left[\mathrm{Sn}(\mathrm{II}) \mathrm{EH}_{2}\right]_{0}=1 /$ $0.05 / 0.15 / 0.4$ in anisole at $35{ }^{\circ} \mathrm{C}$. Polymerization was stopped after 2-3 h when conversion of MIMA reached 50-60\%, based on ${ }^{1} \mathrm{H}-\mathrm{NMR}$ analysis. After the purification by extensive precipitation from $\mathrm{MeOH}$ and following filtration with a basic alumina column, the resulting CoPMIMA copolymers were characterized for chemical structures by ${ }^{1} \mathrm{H}$-NMR spectroscopy and molecular weight by GPC. As a typical example with CoPMIMA-2, ${ }^{1}$ H-NMR spectrum in Fig. S2 $\uparrow$ shows the presence of furan-protected maleimide groups at 6.5, 5.1, and $2.9 \mathrm{ppm}$, ethylhexyl ester groups at $3.6 \mathrm{ppm}$, and phenyl groups in initiating moieties at 7.1-7.3 ppm. The DP was determined by their integral ratio to be 16 for MIMA and 16 for EHMA units. GPC analysis indicates molecular weight as the number average molecular weight $\left(M_{\mathrm{n}}\right)=5.9 \mathrm{~kg} \mathrm{~mol}{ }^{-1}$, with molecular weight distribution as $M_{\mathrm{w}} / M_{\mathrm{n}}=1.5$. In similar ways, CoPMIMA-1 and CoPMIMA-3 were analyzed (Fig. S3 and S4 $\uparrow$ for ${ }^{1} \mathrm{H}$-NMR spectra and Fig. S5 $\dagger$ for GPC traces). Table 1 summarizes the characteristics and results of CoPMIMA copolymers.

The second step is the deprotection of furan groups from furan-protected maleimide pendants to synthesize CoPMA. This 
a)

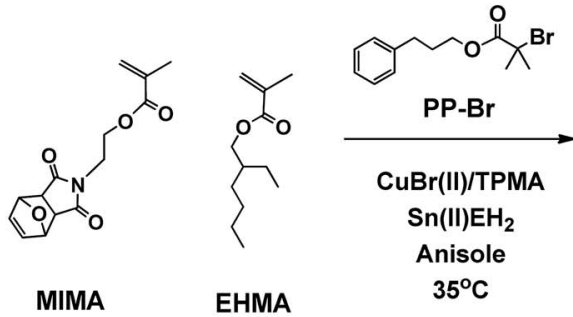

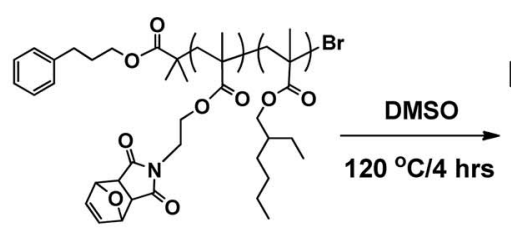

COPMIMA

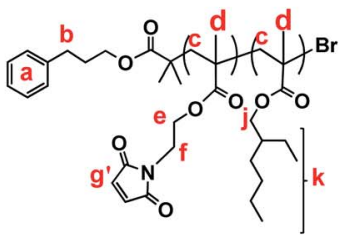

CoPMA

b)

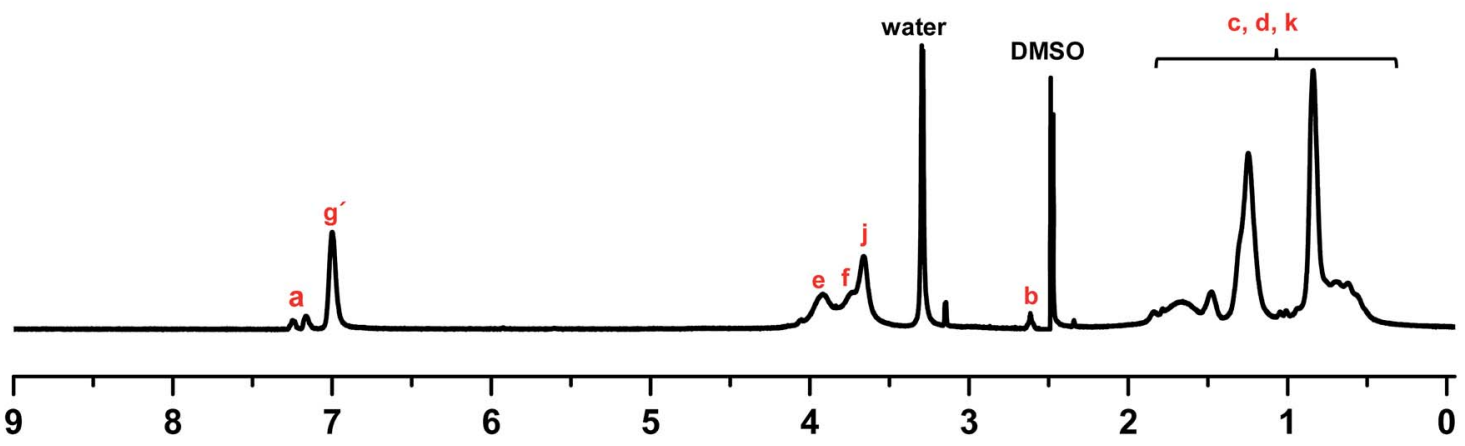

Chemical shift (ppm)

c)

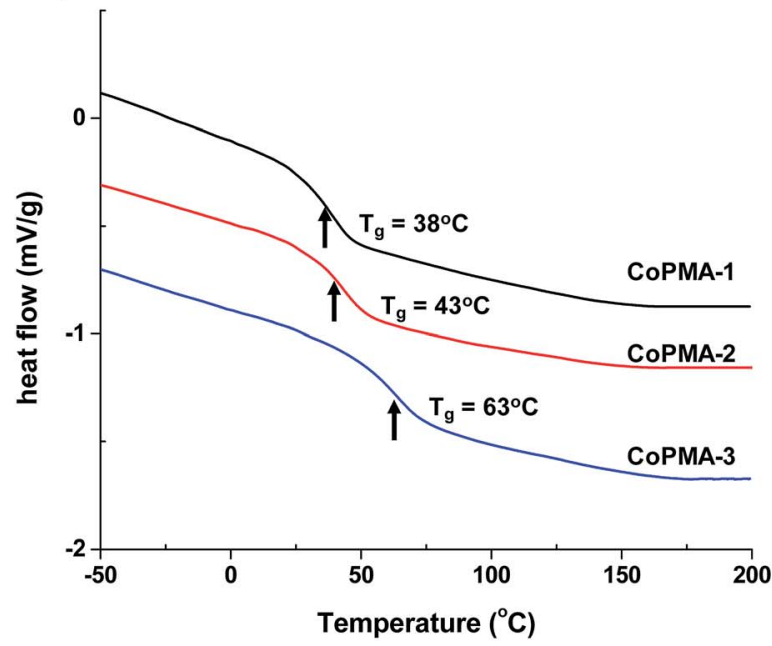

d)

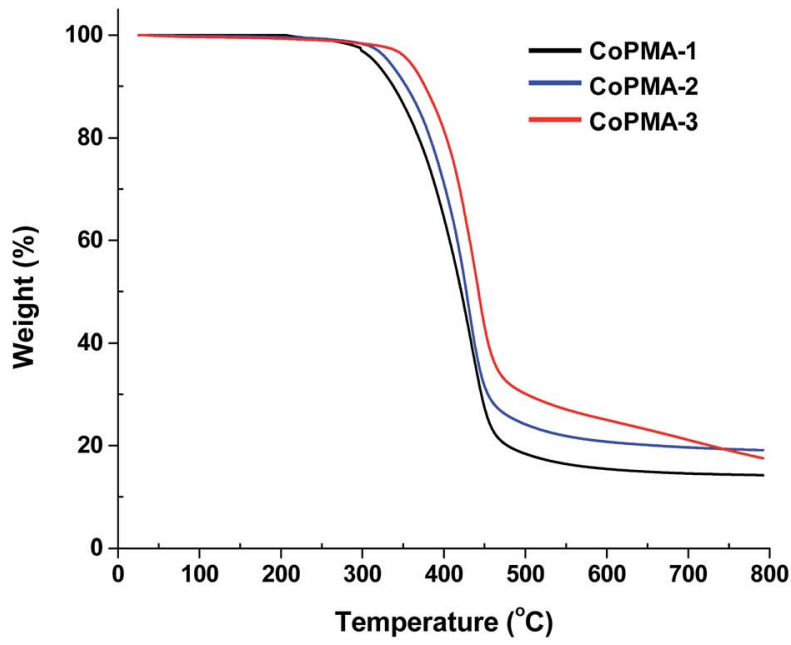

Fig. 1 Synthetic route to CoPMA bearing pendent maleimide groups (a), ${ }^{1} \mathrm{H}-\mathrm{NMR}$ spectrum of CoPMA-2 as an example in DMSO- $d_{6}$ (b), DSC (c), and TGA (d) histograms of CoPMA.

Table 1 Characteristics and properties of CoPMIMA and CoPMA ${ }^{a}$

\begin{tabular}{|c|c|c|c|c|c|c|c|c|}
\hline Entry no. & \multicolumn{2}{|c|}{ MIMA (mol\%) } & \multicolumn{2}{|l|}{$\mathrm{DP}^{b}$} & \multicolumn{2}{|c|}{$M_{\mathrm{n}}\left(\mathrm{kg} \mathrm{mol}^{-1}\right)$} & $M_{\mathrm{w}} / M_{\mathrm{n}}{ }^{c}$ & CoPMA $T_{\mathrm{g}}{ }^{d}\left({ }^{\circ} \mathrm{C}\right)$ \\
\hline CoPMIMA-2 & 50 & 50 & 16 & 16 & 7.3 & 5.9 & 1.5 & 43 \\
\hline CoPMIMA-3 & 75 & 75 & 20 & 7 & 7.1 & 7.4 & 1.7 & 63 \\
\hline
\end{tabular}

${ }^{a}$ Condition for ARGET ATRP: $[\mathrm{MIMA}+\mathrm{EHMA}]_{\mathrm{o}} /[\mathrm{PP}-\mathrm{Br}]_{\mathrm{o}} /[\mathrm{CuBr}(\mathrm{II})]_{\mathrm{o}} /[\mathrm{TPMA}]_{\mathrm{o}} /\left[\mathrm{Sn}(\mathrm{II}) \mathrm{EH}_{2}\right]_{\mathrm{o}}=50 / 1 / 0.05 / 0.15 / 0.4,[\mathrm{monomer}]=1.76 \mathrm{M} ; 35{ }^{\circ} \mathrm{C}$. ${ }^{b}$ Determined by ${ }^{1} \mathrm{H}$-NMR. ${ }^{c}$ Determined by THF GPC with PMMA standards. ${ }^{d}$ Determined by DSC. 
step was simply achieved by heating the solution of the purified CoPMIMA dissolved in DMSO at $120{ }^{\circ} \mathrm{C}$ for $3 \mathrm{~h} .{ }^{1} \mathrm{H}-\mathrm{NMR}$ spectrum of CoPMA-2 in Fig. 1b shows the disappearance of characteristic peaks corresponding to furan aromatic protons and the appearance of new peak $\left(\mathrm{g}^{\prime}\right)$ corresponding to maleimide double bond protons, suggesting $>99 \%$ efficiency. Similar results were observed for CoPMA-1 and CoPMA-3 (Fig. S3 and $\mathrm{S} 4 \dagger$ ). These results confirm the successful synthesis of CoPMA with different densities of pendant maleimide groups.

The synthesized CoPMIMA and CoPMA were examined for their thermal properties using DSC and TGA. For all series of CoPMIMA, their glass transitions could not be clearly detected. However, their DSC diagrams exhibit a strong thermal transition at $100-180^{\circ} \mathrm{C}$, which is due to the loss of furan groups from furan-protected maleimide pendants. Such loss was also clearly observed in their TGA traces at $150-180{ }^{\circ} \mathrm{C}$ (Fig. S6†). In contrast, DSC traces of CoPMA copolymer in Fig. 1c exhibit single transitions at 38,43 , and $63{ }^{\circ} \mathrm{C}$; these $T_{\mathrm{g}}$ values increased with an increasing density of maleimide pendants in copolymers. TGA traces in Fig. 1d show a progressive decomposition of the copolymers to $500{ }^{\circ} \mathrm{C}$. Similarly, the on-set temperature of starting thermal decomposition increased from 300 to $350{ }^{\circ} \mathrm{C}$, suggesting that the enhanced thermal stability with an increasing amount of maleimide pendants in the copolymers.

\section{Synthesis of a trifunctional furan (TFu)}

As illustrated in Fig. 2a, a thermally-induced radical addition of Fu-SH to TMA in the presence of AMBN, an azo-type radical initiator, was examined to synthesize TFu. Excess Fu-SH should be used to minimize undesired side reaction through free radical homopolymerization of methacrylate groups in $\mathrm{TFu} .{ }^{1} \mathrm{H}$ NMR spectrum in Fig. 2b shows the appearance of new peaks corresponding to furan groups $(\mathrm{a}, \mathrm{b}, \mathrm{c})$ and the complete

a)<smiles>C=C(C)C(=O)OCC(C)(COC(=O)C(=C)C)COC(=O)C(=C)C</smiles>

TMA<smiles>SCc1ccc(CS)o1</smiles>

Fu-SH

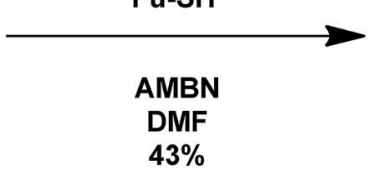<smiles>CC(CSCc1ccco1)C(=O)OCC(C(C)C)C(COC(=O)C(C)CSCc1ccco1)(COC(=O)C(C)CSCc1ccco1)C(C)C</smiles>

b)

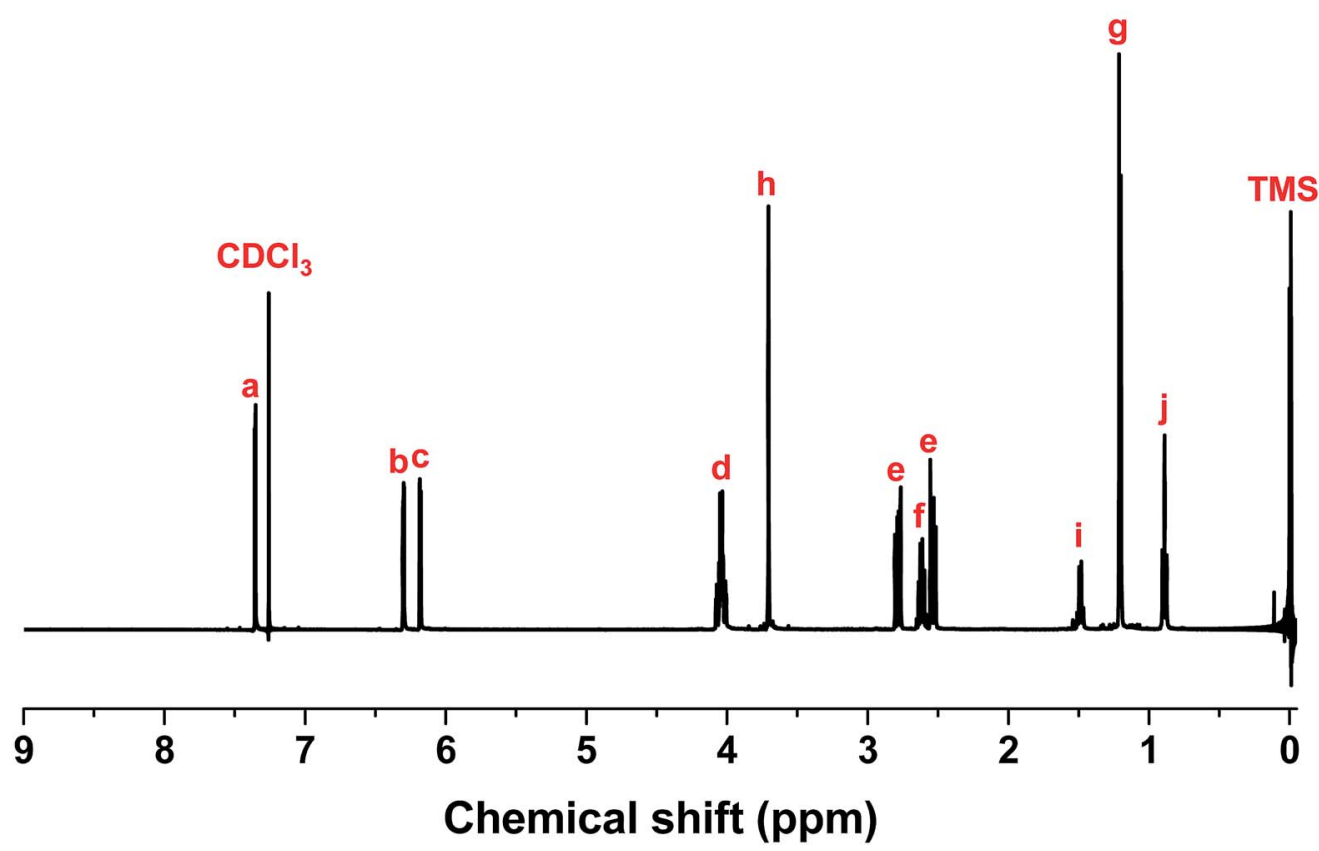

Fig. 2 For TFu, synthetic scheme (a) and ${ }^{1} \mathrm{H}-\mathrm{NMR}$ spectrum in $\mathrm{CDCl}_{3}$ (b). 
disappearance of peaks corresponding to methacrylate groups at 5-6 ppm. In addition to ${ }^{1} \mathrm{H}-\mathrm{NMR},{ }^{13} \mathrm{C}-\mathrm{NMR}$ spectrum in Fig. $\mathrm{S} 7 \dagger$ also confirms the successful synthesis of $\mathrm{TFu}$.

\section{Preparation and characterization of DA-crosslinked networks}

As illustrated in Scheme 1, thermally-induced DA reactions between pendant maleimide groups in CoPMA and furan groups in TFu yields DA-crosslinked networks. With the selected CoPMA-2 (50 mol\% maleimide group), the different mole equivalent ratios of furan to maleimide group in reactive blends of CoPMA and TFu were varied to adjust the mobility of polymeric chains and flexibility of crosslinked networks, thus effective self-healing and enhanced mechanical properties.

A series of reactive blends consisting of CoPMA-2 and TFu at the different mole equivalent ratios of furan/maleimide group $=$ $1 / 1,2 / 1$, and $3 / 1$ were prepared in anisole at $43 \mathrm{wt} \%$. Aliquots of the mixtures were cast on glass plates at room temperature and $60{ }^{\circ} \mathrm{C}$. Note that the formed films denote as F1M1, F2M1, and F3M1 for $1 / 1,2 / 1$, and 3/1 furan/maleimide ratio. They were then characterized with gel content measurements, spectroscopic and thermal analysis. For gel content determination based on solubility in an organic solvent, aliquots of the cast films were soaked in THF for 2 days and insoluble species were isolated and dried. Note that gels here can be defined as insoluble species in THF. As seen in Fig. 3d, the gel content was
$97 \%$ for the cast film with $1 / 1$ furan/maleimide at $60{ }^{\circ} \mathrm{C}$, which could be attributed to the occurrence of DA-crosslinking reactions between pendant maleimide groups of CoPMA and furfuryl groups of $\mathrm{TFu}$ in the reactive mixtures. It decreased to $92 \%$ and further to $78 \%$ as the furan/maleimide ratio increased to $2 /$ 1 and further to $3 / 1$ (excess furan). Promisingly, the films cast at room temperature had the gel content to be 93,87 , and $67 \%$ corresponding to $1 / 1,2 / 1$, and $3 / 1$ ratio. These quantities appeared to be smaller, compared to those for the films cast at $60{ }^{\circ} \mathrm{C}$, presumably due to greater efficiency of DA reactions at $60{ }^{\circ} \mathrm{C}$ than room temperature. Nevertheless, our system consisting of CoPMA and TFu enabled to the formation of thermolabile networks induced even at room temperature. Further, the feasibility to the formation of DA-crosslinked networks at room temperature was confirmed by sol-gel transition experiments. As seen in Fig. 3a-c, the reactive solutions consisting of CoPMA2 and TFu turned to standing gels at room temperature in $12 \mathrm{~h}$ or earlier.

\section{Spectroscopic and thermal analysis of DA-crosslinked networks}

FT-IR was used to characterize the DA-crosslinked films denoted as F1M1, F2M1, and F3M1 cast at room temperature. Fig. 3e shows their FT-IR spectra, compared with those of individual CoPMA and TFu. First, the peak at $1502 \mathrm{~cm}^{-1}$ and $1012 \mathrm{~cm}^{-1}$
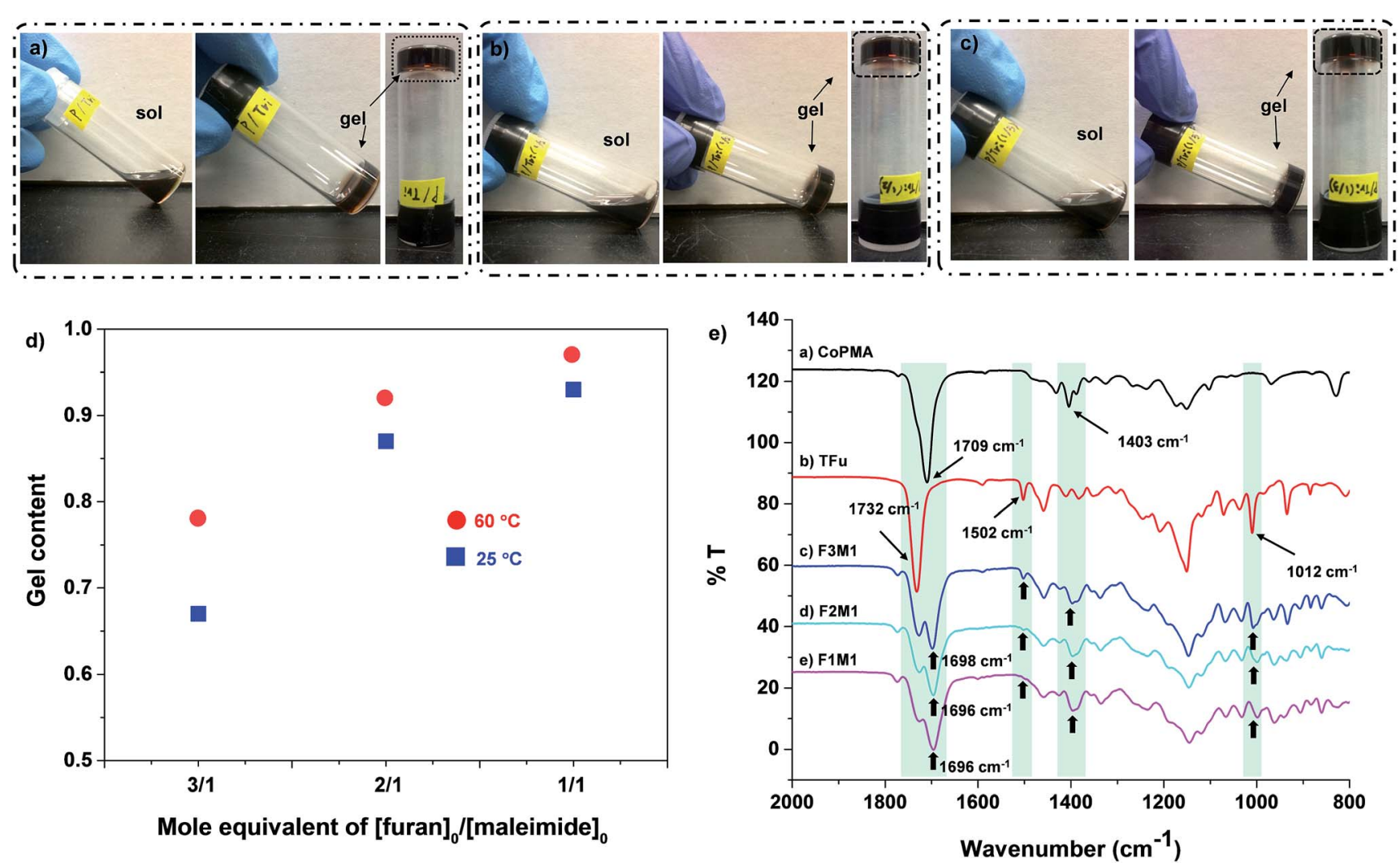

Fig. 3 Digital images illustrating gelation of a series of reactive mixtures of CoPMA-2 and TFu at different mole equivalent ratios of furan/ maleimide $=1 / 1$ (a), 2/1 (b), and 3/1 (c) in anisole at $43 \mathrm{wt} \%$ at room temperature for $12 \mathrm{~h}$ as well as characterization of DA-crosslinked films from reactive blends of CoPMA-2 and TFu at different mole ratios of furan/maleimide = 3/1 (F3M1), 2/1 (F2M1), and 1/1 (F1M1); gel contents cast at room $\left(25^{\circ} \mathrm{C}\right)$ and moderate temperature $\left(60^{\circ} \mathrm{C}\right)(\mathrm{d})$ and FT-IR spectra of films cast at room temperature, compared with CoPMA and TFu (e). 
corresponding to furan rings decreased to disappeared as the furan/maleimide ratio decreased from 3/1 (excess furan) to $1 / 1$. Second, the characteristic peak at $1403 \mathrm{~cm}^{-1}$ for maleimide groups in CoPMA was not detected; rather, broad peaks appeared in DA-crosslinked films. Third, the peaks corresponding to ester carbonyl groups appeared to be broad with one relatively small peak at $1732 \mathrm{~cm}^{-1}$ corresponding to residual furan groups and the other new peak at 1696-1698 $\mathrm{cm}^{-1}$. Such changes are attributed to the formation of DA cycloadducts in the cast films.

Further, DSC and TGA were used to examine the thermal property of the DA-crosslinked films cast at 25 and $60{ }^{\circ} \mathrm{C}$ (Fig. S8†). DSC diagrams of the films cast at $60^{\circ} \mathrm{C}$ show a large endotherm peak between 90 and $200{ }^{\circ} \mathrm{C}$ for all films, suggesting the occurrence of rDA reaction which can be originated from the cleavage of DA-linkage. Similar DSC results were obtained for the films cast at room temperature. In addition, TGA traces suggest that all the DA-crosslinked films are thermally stable up to $300{ }^{\circ} \mathrm{C}$, regardless of the composition of furan and maleimide groups and casting temperature.

\section{Thermoreversibility and self-healing studies}

First, the occurrence of thermally-induced rDA reaction in DAcrosslinked networks was examined with the standing gels formed from F1M1 in anisole at 43\% (see Fig. 4a). As seen in
Fig. $4 \mathrm{~b}-\mathrm{d}$, a piece of the gel was mixed with DMF in a vial. The resulting mixture was heated at $150{ }^{\circ} \mathrm{C}$ for $5 \mathrm{~h}$ to form sol, suggesting the occurrence of rDA reaction. After being cool down to room temperature and placed for $48 \mathrm{~h}$, the sol solution turned to free-standing gel again through DA reaction, proving thermoreversibility of our system.

Given promising results, three films cast at $60{ }^{\circ} \mathrm{C}$ were studied for self-healing at $150{ }^{\circ} \mathrm{C}$. First, micron-sized cuts were made using a blade. They were placed in an oven preset at $150{ }^{\circ} \mathrm{C}$ for $5 \mathrm{~h}$, promoting the occurrence of rDA reactions, and then $80{ }^{\circ} \mathrm{C}$ for $2 \mathrm{~h}$, allowing for the occurrence of DA reactions. Fig. 5 shows optical microscope images of the cuts on the films before and after self-healing. Note that cuts were presented as black-colored straight parts in all the images before healing. For the F1M1 and F2M1 films, the cuts with 20-30 $\mu \mathrm{m}$ wide did not appeared to be completely healed; however, note that F2M1 film shows better healing, compared with F1M1 film (Fig. 5a and b). For the F3M1 film, promisingly, the cuts with 50-100 $\mu \mathrm{m}$ wide (larger than those in F1M1 and F2M1 films) completely healed through void-filling and following rDA/DA crosslinking (Fig. 5c). As seen in Fig. 5c (inset), the F3M1 film is tough, but elastic to be vented and recovered in shape. This property could be attributed to a combination of dangling chains and crosslinking density through the formulation of excess furan groups in the networks. These results suggest the better approach in the design of self-healing networks with excess functional
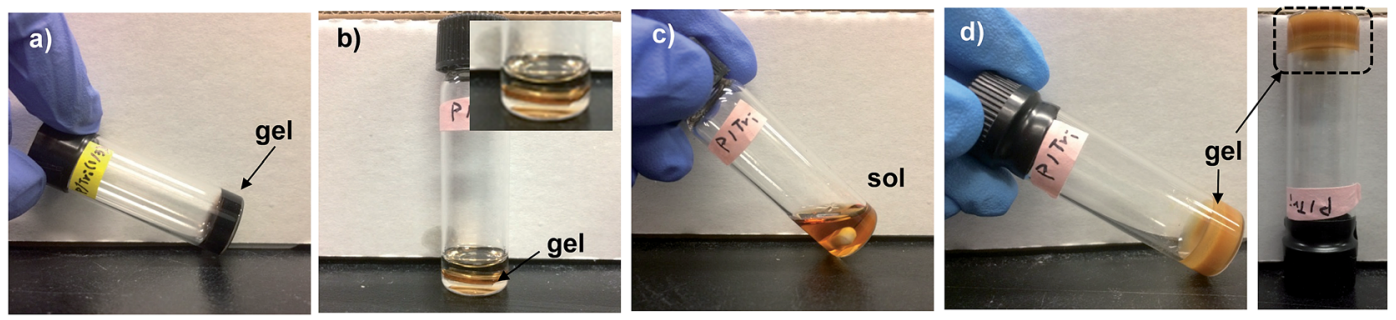

Fig. 4 To illustrate the occurrence of rDA/DA reaction in F1M1 gel, digital images of standing gel formed at $25^{\circ} \mathrm{C} / 12 \mathrm{~h}$ (a), a mixture of a piece of gel with DMF (b), sol formed upon heating at $150{ }^{\circ} \mathrm{C}$ for $5 \mathrm{~h}$ (c), and gel formed upon cooling to room temperature (d).
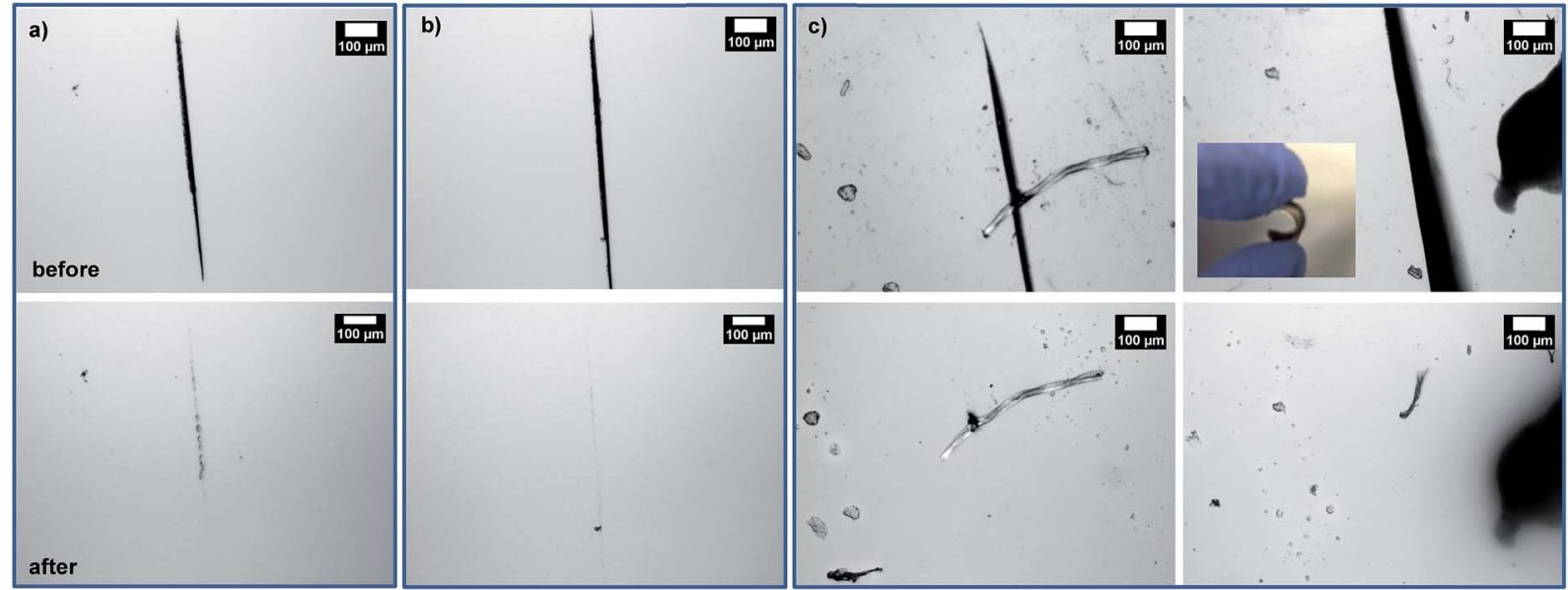

Fig. 5 Optical microscope images of cuts on DA-crosslinked F1M1 (a), F2M1 (b), and F3M1 (c) films before and after being annealed at $150{ }^{\circ} \mathrm{C}$ for $5 \mathrm{~h}$ and following $80^{\circ} \mathrm{C}$ for $2 \mathrm{~h}$. Inset of (c) digital image of F3M1 film. 

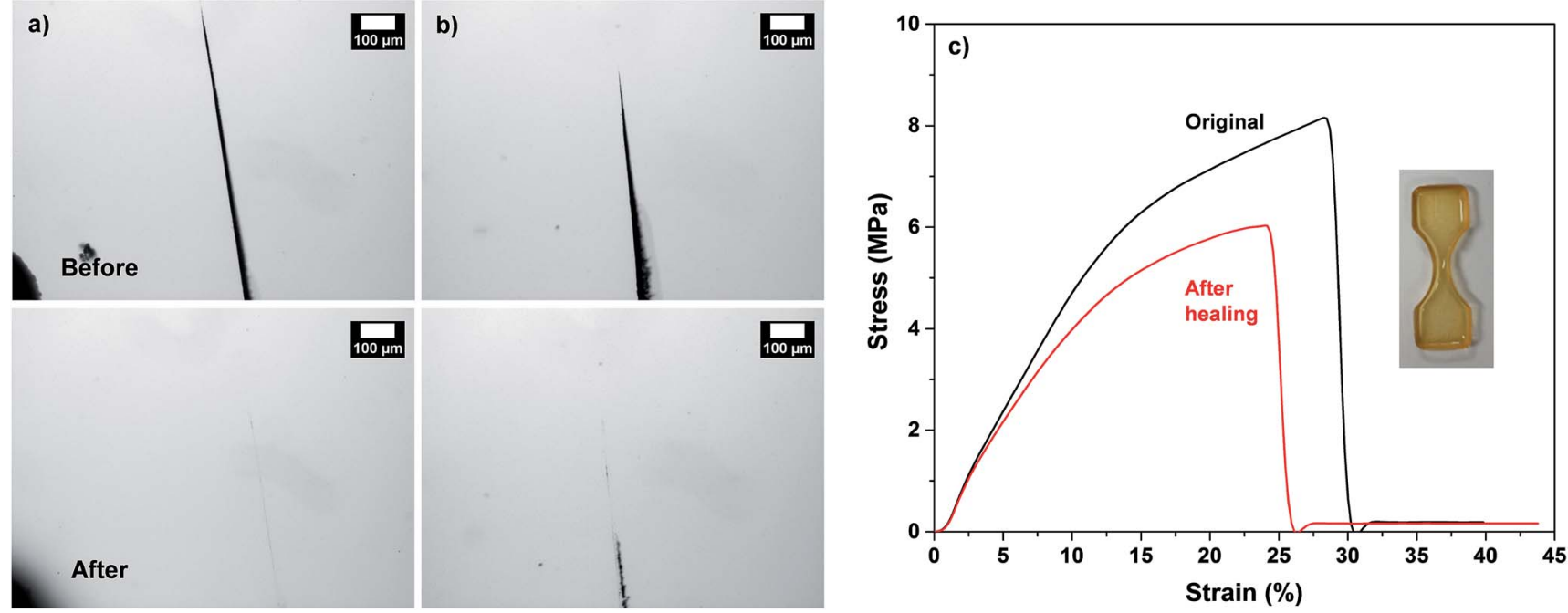

Fig. 6 For DA-crosslinked F3M1 films cast at $60^{\circ} \mathrm{C}$, optical microscope images with different sizes of cuts (a and b) and stress-strain curves (c) before and after being annealed at $110^{\circ} \mathrm{C}$ and following $80^{\circ} \mathrm{C}$.

groups in soft components. Furthermore, the efficiency (or kinetics) of self-healing rely on the width and length of cuts.

In another set, the feasibility to self-healing through the occurrence of dynamic rDA and DA reactions at low temperatures was examined, with the selected F3M1 film. As seen in Fig. $6 a$ and b, when the films were annealed at $110^{\circ} \mathrm{C}$ for $5 \mathrm{~h}$, the occurrence of healing was observed. Further, the extent of thermal healing was relied on the width of cuts. At temperature as low as $85^{\circ} \mathrm{C}$, the important healing was not observed over 3 days (Fig. S9†), suggesting that enough thermal energy could be required for the occurrence of rDA reactions in our system consisting of F3M1.

\section{Self-healing viscoelastic and mechanical properties}

Quantitative analysis of self-healing behavior was followed with tensile measurements. Dumbbell-shaped specimens were prepared from F3M1 reactive mixtures (inset in Fig. 6c). A small micron-sized crack was made using a blade on the center of the specimens. The scratched specimens were subjected to thermal annealing process at $110^{\circ} \mathrm{C}$ for $2 \mathrm{~h}$ and then $60^{\circ} \mathrm{C}$ for $24 \mathrm{~h}$ to promote self-healing through rDA/DA reactions. Fig. $6 \mathrm{c}$ compares stress and strain curves of DA-crosslinked films before and after self-healing. The tensile strength at break decreased from 8 to $6 \mathrm{MPa}$ as well as its elongation also decreased from 30 to $26 \%$ by $4 \%$, indicating $>85 \%$ healing efficiency upon one healing event. The decrease in tensile strength and elongation at break is presumably attributed to the existence of invisible defects in cuts that could be caused by rearrangement of polymeric chains (void-filling) and incomplete $\mathrm{rDA} / \mathrm{DA}$ reactions during self-healing process at $110^{\circ} \mathrm{C}$.

Further to get an insight into elasticity for self-healing of the crosslinked polymeric networks, their viscoelastic properties were measured using a rheometer with a cyclic change of oscillation force: $5 \%$ strain for $1500 \mathrm{~s}$ to $100 \%$ strain for $500 \mathrm{~s}$. As seen in Fig. 7, the elastic modulus $\left(G^{\prime}\right)$ of the crosslinked

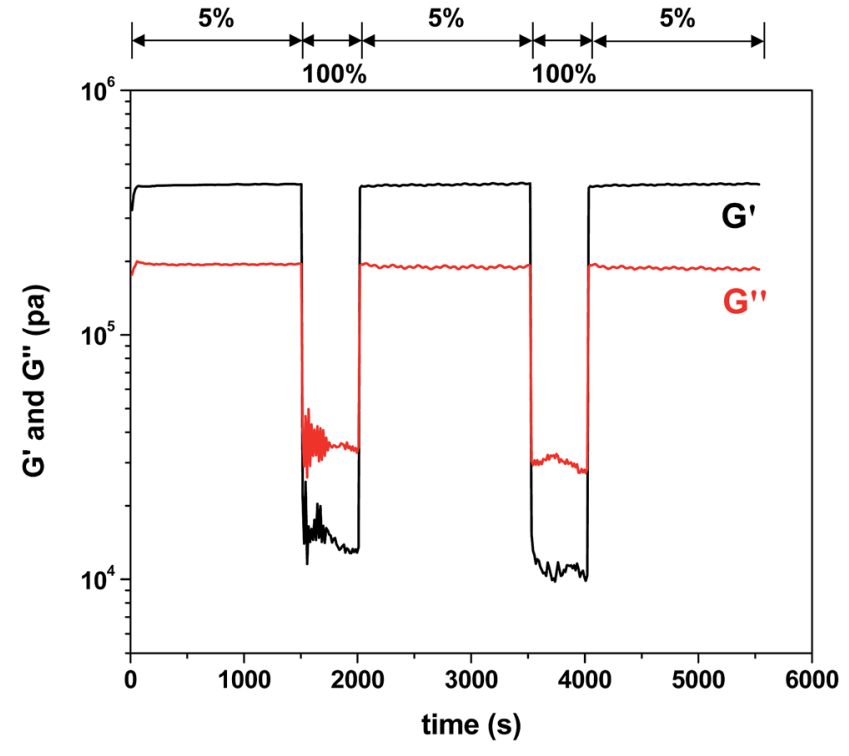

Fig. 7 Viscoelastic properties upon a cyclic change of oscillation force: $5 \%$ strain for 1500 s to $100 \%$ strain for 500 s for crosslinked F3M1 films cast at $60^{\circ} \mathrm{C}$.

films was $4.5 \times 10^{5}$ Pa when a $5 \%$ strain was applied. Upon the change of oscillation force to $100 \%$ strain, the $G^{\prime}$ modulus dropped to $1.2 \times 10^{4} \mathrm{~Pa}$. Then, the $G^{\prime}$ modulus was restored when the oscillation force was recovered back to $5 \%$ strain. Such a reversible restoration of $G^{\prime}$ modulus was able to be repeated several times, exhibiting self-healing elasticity of the crosslinked polymeric networks.

\section{Conclusion}

New random CoPMA with different densities of pendant maleimide and ethylhexyl groups were synthesized by two steps, including ARGET ATRP to CoPMIMA precursors and following 
deprotection of pendant furan-protected maleimide groups to the corresponding maleimide groups. Their structural and thermal analysis indicate that the synthesized CoPMA copolymers had the molecular weights mostly ranging at $7-8 \mathrm{~kg} \mathrm{~mol}^{-1}$ by ${ }^{1} \mathrm{H}-\mathrm{NMR}$, while their thermal transitions varied from 38 to $63{ }^{\circ} \mathrm{C}$ with an increasing amount of maleimide groups from 40 to $75 \mathrm{~mol} \%$ in the copolymers. Reactive blends of the resultant CoPMA with TFu at different mole ratios of furan/maleimide groups allowed for the fabrication of thermo-labile networks with adjustable network flexibility at room and moderate temperatures $\left(60{ }^{\circ} \mathrm{C}\right)$, confirmed by gel content, sol-gel transition, spectroscopic and thermal analysis. Thermoreversible selfhealing studies through optical microscopy, tensile and viscoelastic measurements suggest that the use of excess of TFu enhanced the mobility and flexibility of the networks; ultimately, the thermoreversible networks had excellent selfhealability with great mechanical strength recovery as well as self-healing elasticity with reversible restoration of viscoelastic properties.

\section{Acknowledgements}

Authors greatly thank for financial supports from Canada Research Chair (CRC) Award and Korea Research Institute of Chemical Technology (KRICT). Additionally, a partial support from The Ministry of Trade, Industry \& Energy Korea (Industrial Technology Innovation Program No. 10067082) is greatly acknowledged. JKO is a Tier II CRC (renewed) in Nanobioscience. Authors thank So Young An for her helpful discussions.

\section{References}

1 M. Cabodi, N. W. Choi, J. P. Gleghorn, C. S. D. Lee, L. J. Bonassar and A. D. Stroock, J. Am. Chem. Soc., 2005, 127, 13788.

2 N. W. Choi, M. Cabodi, B. Held, J. P. Gleghorn, L. J. Bonassar and A. D. Stroock, Nat. Mater., 2007, 6, 908.

3 M. Ooka and H. Ozawa, Prog. Org. Coat., 1994, 23, 325.

4 B. J. Blaiszik, S. L. B. Kramer, S. C. Olugebefola, J. S. Moore, N. R. Sottos and S. R. White, Annu. Rev. Mater. Res., 2010, 40, 179.

5 S. Burattini, B. W. Greenland, D. Chappell, H. M. Colquhoun and W. Hayes, Chem. Soc. Rev., 2010, 39, 1973.

6 S. Y. An, D. Arunbabu, S. M. Noh, Y. K. Song and J. K. Oh, Chem. Commun., 2015, 51, 13058.

7 D. G. Shchukin, Polym. Chem., 2013, 4, 4871.

8 Y.-K. Song and C.-M. Chung, Polym. Chem., 2013, 4, 4940.

9 E. B. Murphy and F. Wudl, Prog. Polym. Sci., 2010, 35, 223.

10 R. Vaiyapuri, B. W. Greenland, H. M. Colquhoun, J. M. Elliott and W. Hayes, Polym. Chem., 2013, 4, 4902.

11 L. R. Hart, J. L. Harries, B. W. Greenland, H. M. Colquhoun and W. Hayes, Polym. Chem., 2013, 4, 4860.

12 Z. Wei, J. He, T. Liang, H. Oh, J. Athas, Z. Tong, C. Wang and Z. Nie, Polym. Chem., 2013, 4, 4601.

13 J. Zheng, P. Xiao, W. Liu, J. Zhang, Y. Huang and T. Chen, Macromol. Rapid Commun., 2016, 37, 265.
14 X. Yan, D. Xu, J. Chen, M. Zhang, B. Hu, Y. Yu and F. Huang, Polym. Chem., 2013, 4, 3312.

15 M. Krogsgaard, M. A. Behrens, J. S. Pedersen and H. Birkedal, Biomacromolecules, 2013, 14, 297.

16 Z. Wang and M. W. Urban, Polym. Chem., 2013, 4, 4897.

17 S. Basak, J. Nanda and A. Banerjee, Chem. Commun., 2014, 50, 2356.

18 F. Potier, A. Guinault, S. Delalande, C. Sanchez, F. Ribot and L. Rozes, Polym. Chem., 2014, 5, 4474.

19 Z. Wang, W. Fan, R. Tong, X. Lu and H. Xia, RSC Adv., 2014, 4, 25486.

20 C.-H. Li, C. Wang, C. Keplinger, J.-L. Zuo, L. Jin, Y. Sun, P. Zheng, Y. Cao, F. Lissel, C. Linder, X.-Z. You and Z. Bao, Nat. Chem., 2016, 8, 618.

21 Y. Chen and Z. Guan, Polym. Chem., 2013, 4, 4885.

22 Y. Chen and Z. Guan, Chem. Commun., 2014, 50, 10868.

23 Y. Lin and G. Li, J. Mater. Chem. B, 2014, 2, 6878.

24 J. Hentschel, A. M. Kushner, J. Ziller and Z. Guan, Angew. Chem., Int. Ed., 2012, 51, 10561.

25 S. Chen, N. Mahmood, M. Beiner and W. H. Binder, Angew. Chem., Int. Ed., 2015, 54, 10188.

26 X. Yang, H. Yu, L. Wang, R. Tong, M. Akram, Y. Chen and X. Zhai, Soft Matter, 2015, 11, 1242.

27 P. Michael, D. Doehler and W. H. Binder, Polymer, 2015, 69, 216.

28 D. Zhu, Q. Ye, X. Lu and Q. Lu, Polym. Chem., 2015, 6, 5086. 29 C. Xu, L. Cao, B. Lin, X. Liang and Y. Chen, ACS Appl. Mater. Interfaces, 2016, 8, 17728.

30 M. Nakahata, Y. Takashima, H. Yamaguchi and A. Harada, Nat. Commun., 2011, 2, 511.

31 H. Ying, Y. Zhang and J. Cheng, Nat. Commun., 2014, 5, 4218/ 1.

32 H. Ying and J. Cheng, J. Am. Chem. Soc., 2014, 136, 16974.

33 S. Y. An, S. M. Noh, J. H. Nam and J. K. Oh, Macromol. Rapid Commun., 2015, 36, 1255.

34 Z. P. Zhang, M. Z. Rong, M. Q. Zhang and C.-e. Yuan, Polym. Chem., 2013, 4, 4648.

35 C. e. Yuan, M. Z. Rong, M. Q. Zhang, Z. P. Zhang and Y. C. Yuan, Chem. Mater., 2011, 23, 5076.

36 K. Imato, M. Nishihara, T. Kanehara, Y. Amamoto, A. Takahara and H. Otsuka, Angew. Chem., Int. Ed., 2012, 51, 1138.

37 J. J. Cash, T. Kubo, A. P. Bapat and B. S. Sumerlin, Macromolecules, 2015, 48, 2098.

38 O. R. Cromwell, J. Chung and Z. Guan, J. Am. Chem. Soc., 2015, 137, 6492.

39 H. Meng, P. Xiao, J. Gu, X. Wen, J. Xu, C. Zhao, J. Zhang and T. Chen, Chem. Commun., 2014, 50, 12277.

$40 \mathrm{~J}$. Canadell, H. Goossens and B. Klumperman, Macromolecules, 2011, 44, 2536.

41 M. Pepels, I. Filot, B. Klumperman and H. Goossens, Polym. Chem., 2013, 4, 4955.

42 J. A. Yoon, J. Kamada, K. Koynov, J. Mohin, R. Nicolaÿ, Y. Zhang, A. C. Balazs, T. Kowalewski and K. Matyjaszewski, Macromolecules, 2012, 45, 142.

43 G. Deng, F. Li, H. Yu, F. Liu, C. Liu, W. Sun, H. Jiang and Y. Chen, ACS Macro Lett., 2012, 1, 275. 
44 A. Rekondo, R. Martin, A. Ruiz de Luzuriaga, G. Cabanero, H. J. Grande and I. Odriozola, Mater. Horiz., 2014, 1, 237.

45 D. Doehler, H. Peterlik and W. H. Binder, Polymer, 2015, 69, 264.

46 M. A. Tasdelen, Polym. Chem., 2011, 2, 2133.

47 M. Glassner, G. Delaittre, M. Kaupp, J. P. Blinco and C. Barner-Kowollik, J. Am. Chem. Soc., 2012, 134, 7274.

48 X. Chen, M. A. Dam, K. Ono, A. Mal, H. Shen, S. R. Nutt, K. Sheran and F. Wudl, Science, 2002, 295, 1698.

49 E. B. Murphy, E. Bolanos, C. Schaffner-Hamann, F. Wudl, S. R. Nutt and M. L. Auad, Macromolecules, 2008, 41, 5203.

50 R. J. Sheridan and C. N. Bowman, Polym. Chem., 2013, 4, 4974.

51 J. Zhao, R. Xu, G. Luo, J. Wu and H. Xia, J. Mater. Chem. B, 2016, 4, 982.

52 Y. Heo and H. A. Sodano, Adv. Funct. Mater., 2014, 24, 5260.

53 G. B. Lyon, A. Baranek and C. N. Bowman, Adv. Funct. Mater., 2016, 26, 1477.

54 S. Wu, J. Li, G. Zhang, Y. Yao, G. Li, R. Sun and C. Wong, ACS Appl. Mater. Interfaces, 2017, 9, 3040.

55 Y. Heo, M. H. Malakooti and H. A. Sodano, J. Mater. Chem. A, 2016, 4, 17403.
56 L.-T. T. Nguyen, T. T. Truong, H. T. Nguyen, L. Le, V. Q. Nguyen, T. Van Le and A. T. Luu, Polym. Chem., 2015, 6, 3143.

57 J. Zhao, R. Xu, G. Luo, J. Wu and H. Xia, Polym. Chem., 2016, 7, 7278.

58 A. A. Kavitha and N. K. Singha, Macromolecules, 2010, 43, 3193.

59 A. A. Kavitha and N. K. Singha, ACS Appl. Mater. Interfaces, 2009, 1, 1427.

60 N. B. Pramanik, G. B. Nando and N. K. Singha, Polymer, 2015, 69, 349.

61 S. Jung, J. T. Liu, S. H. Hong, D. Arunbabu, S. M. Noh and J. K. Oh, Polymer, 2017, 109, 58.

62 R. K. Bose, J. Koetteritzsch, S. J. Garcia, M. D. Hager, U. S. Schubert and S. van der Zwaag, J. Polym. Sci., Part A: Polym. Chem., 2014, 52, 1669.

63 J. Koetteritzsch, M. D. Hager and U. S. Schubert, Polymer, 2015, 69, 321.

64 J. Koetteritzsch, S. Stumpf, S. Hoeppener, J. Vitz, M. D. Hager and U. S. Schubert, Macromol. Chem. Phys., 2013, 214, 1636.

65 D. Arunbabu, S. M. Noh, J. H. Nam and J. K. Oh, Macromol. Chem. Phys., 2016, 217, 2191.

66 G. J. P. Britovsek, J. England and A. J. P. White, Inorg. Chem., 2005, 44, 8125. 